\title{
Surgical treatment of chronic acromioclavicular joint dislocation with autogenous tendon grafts
}

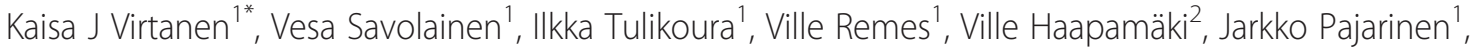 \\ Jan-Magnus Björkenheim ${ }^{1}$ and Mika Paavola ${ }^{1,3}$
}

\begin{abstract}
Background: Conservative treatment of acromioclavicular (AC) joint dislocation is not always successful. A consequence of persistent AC joint dislocation may be chronic pain and discomfort in the shoulder region as well a sensation of constant AC joint instability and impaired shoulder function. Stabilization of the AC joint may reduce these sequels.

Materials and methods: Due to chronic AC joint dislocation, 39 patients in our hospital underwent coracoclavicular (CC) ligament reconstruction with autogenous semitendinosus and gracilis tendons between May 2005 and April 2011. We examined 25 patients after a mean of 4.2 years. The outcomes were Constant shoulder Score (CS), Disabilities of the Arm, Shoulder and Hand (DASH), pain (Visual Analog Scale, VAS), cross-arm test, stability of the AC joint, and complications. The follow-up visits included anteroposterior and axillary radiographs.

Results: Mean CS was 83 in the injured shoulder and 91 in the uninjured shoulder $(p=0.002)$. Mean DASH was 14. In 14 patients, the AC joint was clinically stable; pain was minor. In radiographs, osteolysis of the lateral clavicle and tunnel widening were markedly common. Fracture of the coracoid process occurred in 5 patients, and 3 suffered a fracture of the clavicle; 2 had a postoperative infection.
\end{abstract}

Conclusions: Anatomic reconstruction of CC ligaments showed a moderate subjective outcome at the 4-year follow-up. After surgery, almost half the AC joints failed to stabilize. Lateral clavicle osteolysis and tunnel widening were notably common complications.

Keywords: Chronic acromioclavicular joint dislocation; Delayed surgical treatment; Tendon graft

\section{Background}

Acromioclavicular (AC) joint dislocations are typically classified according to Rockwood, a classification based on degree of soft-tissue injury and clavicle dislocation (Galatz et al. 2009). Clinical assessment of the severity of the AC joint injury is challenging. It is not uncommon that the severity of the injury is misclassified. Sometimes, result of conservative treatment is unsatisfactory. The patient may suffer chronic pain and discomfort in the shoulder region, as well impaired shoulder function (Bannister et al. 1989; Kennedy and Cameron 1954; Song et al. 2012).

To date, the literature abounds in different methods to treat chronic AC joint dislocation (Adam and Farouk

\footnotetext{
* Correspondence: kaisa.virtanen@hus.fi

'Department of Surgery, Helsinki University Central Hospital and University of Helsinki, Topeliuksenkatu 5, Helsinki 00260, Finland

Full list of author information is available at the end of the article
}

2004; Bostrom Windhamre et al. 2010; Fraschini et al. 2010; Jeon et al. 2007; Kim et al. 2012; Tauber et al. 2009). No one of these methods seems superior. Anatomic reconstruction of coracoclavicular (CC) ligaments with autogenous tendon grafts, widely used in treating chronic AC joint instability, reportedly diminishes pain, eliminates sequels, and improves function as well as strength (Jones et al. 2001; LaPrade and Hilger 2005; Shetty et al. 2009; Tauber et al. 2009; Yoo et al. 2010; Tauber et al. 2007). Semitendinosus and gracilis tendons are evaluated to be strong enough to use as suitable grafts (Hamner et al. 1999).

The aim of our study was to assess the functional and radiological results in chronic AC joint dislocation treated with autogenous semitendinosus and gracilis tendon grafts. Our hypothesis was that results of delayed surgery are satisfactory, but function is inferior to the function of the uninjured side. Before the study began, 
Helsinki University Central Hospital, Ethics Committee, Department of Surgery gave their approval (2004-02-27 66/E6/04). Patients approved the informed consent to participate in the study.

\section{Materials and methods}

In our hospital, between May 2005 and April 2011, 39 patients had surgery for chronic AC joint dislocation. Of 39 patients, 25 participated in a follow-up visit after a mean of 4.2 years (range 1-7 years). The rest 14 patients refused the follow-up visit or did not respond to the invitation. Patient and injury characteristics are shown in Table 1. Indications for delayed surgery were long-term pain or discomfort in the shoulder region and inability to do normal work or daily tasks after unsuccessful conservative treatment (19 patients) or failure of an earlier surgery with persistent pain (6 patients). Mean delay from injury to reconstructive surgery was 435 (range 149-1586) days. In primary radiographs, the majority (15 patients) had Rockwood type V injury.

\section{Surgical technique}

Surgery was performed under general anesthesia by one surgeon. Clindamycin $600 \mathrm{mg}$ antibiotic prophylaxis was administered to each patient, who lay in a standard, beach-chair position. After installing a tourniquet in the thigh, a vertical incision was made over the pes anserinus area. Semitendinosus (ST) and gracilis (G) tendons were identified and harvested by a tendon stripper. The wound was closed in layers. A saber incision was then

Table 1 Patient and injury characteristics in 25 patients treated surgically for chronic AC joint dislocation with autogenous semitendinosus and gracilis tendon grafts

\begin{tabular}{lc}
\hline Male/female & $\mathbf{2 1 / 4}$ \\
\hline $\begin{array}{l}\text { Injured side } \\
\text { Right/left }\end{array}$ & $18 / 7$ \\
Dominance & $21 / 4$ \\
$\quad$ Right/left & \\
Mechanism of primary injury & 9 \\
Bicycling & 7 \\
Simple fall & 7 \\
Sport & 2 \\
Traffic accident & \\
Rockwood type in primary radiographs & 3 \\
II & 6 \\
III & 1 \\
IV & 15 \\
Mean age at time of injury, y (range) & $44(22-59)$ \\
Mean age at time of examination, y (range) & 48 (24-63)
\end{tabular}

made over the $\mathrm{AC}$ joint and distal clavicle. The $\mathrm{AC}$ joint and distal clavicle was exposed by detaching the origin of the deltoid muscle and the insertion of the trapezoid muscle. The coracoid process was exposed by excising the scar tissue and fat pad in the region of the CC ligaments. If a visible osteoarthritis existed in the $\mathrm{AC}$ joint, a 6-8 $\mathrm{mm}$ resection of the distal clavicle was performed with an oscillating saw. At the insertion sites of the CC ligaments in the clavicle were drilled 2 superior-inferior directed $5.5-\mathrm{mm}$ holes. The prepared tendons and 2 FiberWire \#5 (Arthrex, Naples, FL, USA) sutures were transferred under the coracoid process. After the AC joint was reduced manually, the tendons, once pulled through the drill holes, were then attached by $5.5 \times 15$ mm tenodesis screws (Bio-Tenodesis ${ }^{\mathrm{Tm}}$ AR-1555B or PEEK Tenodesis $^{\mathrm{mt}}$ AR-1555PS, Arthrex, Naples, FL, USA). If the tendon graft was sufficient over the AC joint, it was attached to the acromion with $3.5-\mathrm{mm}$ titanium suture anchor (Corkscrew ${ }^{\circ}$, Arthrex) to strengthen the superior AC ligament. Finally, the double FiberWire $\# 5$ sutures (18 patients) were tied over the clavicle. The wound was closed in layers. The arm was immobilized in a sling for 2 to 3 weeks. Postoperatively, pendulum motion was allowed as well as passive abduction and flexion up to the horizontal plane. After 4 weeks the full range of motion was allowed without weight. After 6 months, patients could return to full activity. Detailed information on the surgery is in Table 2.

The outcomes were Constant shoulder Score (CS), Disabilities of the Arm, Shoulder and Hand (DASH), pain (Visual Analog Scale, VAS 0-10), cross-arm test, clinical stability of the AC joint, and complications. Length of sick leave was determined, as was the patient's subjective satisfaction with the end results of the treatment (excellent, good, moderate, poor). From anteroposterior (AP) and axillary radiographs, we evaluated alignment of the $\mathrm{AC}$ joint, $\mathrm{AC}$ joint osteoarthritis,

Table 2 Description of surgery in the $\mathbf{2 5}$ patients treated for chronic AC joint dislocation

\begin{tabular}{|c|c|}
\hline Detail & $\mathrm{n}=\mathbf{2 5}$ \\
\hline Resection of lateral end of clavicle & 10 \\
\hline PEEK Tenodesis ${ }^{\mathrm{TM}}$ screws $(5.5 \times 15 \mathrm{~mm})$ & 8 \\
\hline Bio-Tenodesis ${ }^{\mathrm{TM}}$ screws $(5.5 \times 15 \mathrm{~mm})$ & 17 \\
\hline Strengthening of superior AC ligament & 18 \\
\hline FiberWire $^{\circledast}(\# 5)$ augmentation & 18 \\
\hline Semitendinosus graft & 25 \\
\hline \multirow[t]{2}{*}{ Gracilis graft } & 21 \\
\hline & Minutes \\
\hline Mean duration of surgery* (range) & $112(71-180)$ \\
\hline
\end{tabular}

$\mathrm{AC}=$ acromioclavicular.

$\mathrm{PEEK}=$ polyetheretherketone.

*Duration with tendon harvesting. 
osteolysis of the lateral clavicle, and possible complications. The surgery and clinical examination was performed by separate persons.

\section{Statistcs}

Statistical analysis was performed with SPSS Statistics (version 21.0, IBM, USA). We used the KolmogorovSmirnov test for normality. The CS between the injured and uninjured shoulder was analyzed by paired-samples T-test. Nominal variables were analyzed by Fisher's exact test. For all tests a 2 -sided level of 0.05 was considered significant.

\section{Results}

The mean CS was 83 (range 55-100) for the injured shoulder and 91 (range 77-100) for the uninjured shoulder $(\mathrm{p}=0.002)$. The mean DASH was 14 (range $0-58)$. In 14 patients, the $\mathrm{AC}$ joint was clinically stable at follow-up. On the injured side, the cross-arm test was positive in 6 patients (Table 3). Mean length of sick leave after the reconstructive surgery was 109 (range 28-374) days. Of 25 patients, 21 assessed the subjective results as excellent or good.

In the radiographs (AP and axillary) the $\mathrm{AC}$ joint was in normal alignment in 11 patients. After the procedure, lateral clavicle osteolysis (Figure 1) and tunnel widening (Figure 2) were fairly common (Table 4 ). In only 1 patient the osteolysis was seen in the preoperative radiographs. We found no relation between screw material and osteolysis $(\mathrm{p}=0.39)$ or tunnel widening $(\mathrm{p}=0.28)$. Distal clavicle resection seemed not to influence to the incidence of osteolysis $(\mathrm{p}=0.4)$.

Postoperatively, 1 patient had a superficial and 1 patient a deep wound infection. The former was treated with p.o. antibiotics and the latter with i.v. and p.o. antibiotics. The deep wound infection resulted in removal of tendon grafts and screws and healed only after a deltoidmuscle transfer. In 2 patients, reconstructive surgery

Table 3 Clinical outcomes after a mean $\mathbf{4 . 2}$ years in the 25 patients treated surgically for chronic AC joint dislocation

\begin{tabular}{lc}
\hline CS injured shoulder & $\mathbf{n = 2 5}$ \\
CS uninjured shoulder & $83(12)$ \\
DASH & $91(7)$ \\
VAS at rest (0-10) & $14(18)$ \\
VAS at activity (0-10) & $1(2)$ \\
Cross-arm test positive & $3(3)$ \\
AC joint clinically stable & 6 \\
\hline
\end{tabular}

$\mathrm{AC}=$ acromioclavicular.

$\mathrm{CS}=$ Constant shoulder Score.

DASH $=$ Disabilities of the Arm, Shoulder and Hand.

VAS $=$ Visual Analog Scale.

Standard deviation (SD) in parentheses. failed, and these required another identical procedure. Fracture of the coracoid process appeared in 5 patients, and 3 patients had a fracture in the clavicle (Table 5).

In 18 patients, the superior AC ligament was reinforced with a tendon graft. Despite this procedure, in 7 patients their $\mathrm{AC}$ joint was unstable. In comparison, of 7 patients without the AC ligament reinforcement, 3 had an unstable $\mathrm{AC}$ joint. There was no difference between patients with clinically stable AC joint and unstable AC joint in function $(\mathrm{p}=0.7)$, in disability $(\mathrm{p}=0.6)$, or in patient satisfaction $(\mathrm{p}=0.4)$.

We assessed the influence of osteolysis, tunnel widening, and fracture of the coracoid process on function, disability, pain, and AC joint stability. Patients having lateral clavicle osteolysis seemed to have more disability (DASH 19, range 0-58) than patients without it (DASH 8 , range $0-28$ ), although this difference was not statistically significant $(\mathrm{p}=0.2)$ (Table 6$)$.

\section{Discussion}

Sometimes conservative treatment of AC joint dislocation is unsuccessful, or results of surgery are undesirable. Consequences may be persistent pain and insufficiency in the shoulder region, inability to perform overhead activities, and a repeated sense of instability or weakness. In our study, all patients were treated with anatomic reconstruction of the CC ligaments. In most patients, the superior AC ligament was also reinforced. At follow-up, clinical outcomes were moderate. The rate of complications was, however, surprisingly high.

In 1972, Weaver and Dunn published a method to treat chronic AC joint dislocation. The original procedure involved a resection to the lateral end of the clavicle and stabilization of the $\mathrm{AC}$ joint by the acromial end of the shortened coraco-acromial ligament into the medullary canal of the lateral clavicle (Weaver and Dunn 1972). During later decades, several modifications have arisen from the Weaver-Dunn method (Adam and Farouk 2004; Boileau et al. 2010; Bostrom Windhamre et al. 2010; Hosseini et al. 2009; Kim et al. 2012; Lafosse et al. 2005; Millett et al. 2009; Pavlik et al. 2001). Jones et al. (2001) first published a case report discussing reconstruction of CC ligaments by autogenous semitendinosus tendon graft. In chronic AC joint dislocation, earlier studies have evaluated the results of this normal-anatomy-imitating technique (Tauber et al. 2007; Tauber et al. 2009; Yoo et al. 2010; Fauci et al. 2013). These studies have suggested favorable results after surgery.

After the reconstructive surgery, we found satisfactory results for upper limb function and symptoms. CS was better in the uninjured than in the injured shoulder, but we believe that the difference ( 8 points) is not clinically relevant. According to the literature, the normal value of CS in this age group (40-50) is 91 to 96 in male and 83 


\section{a)}

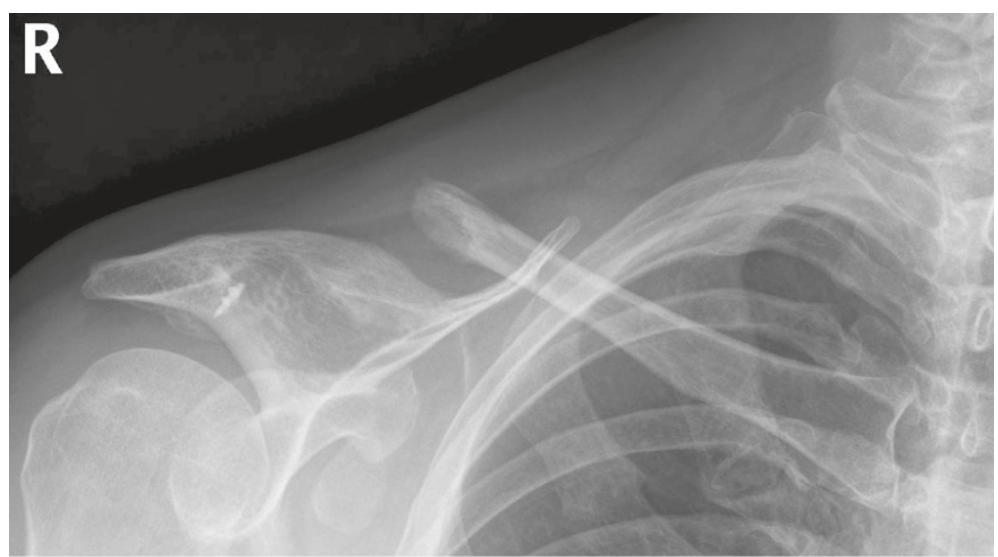

b)

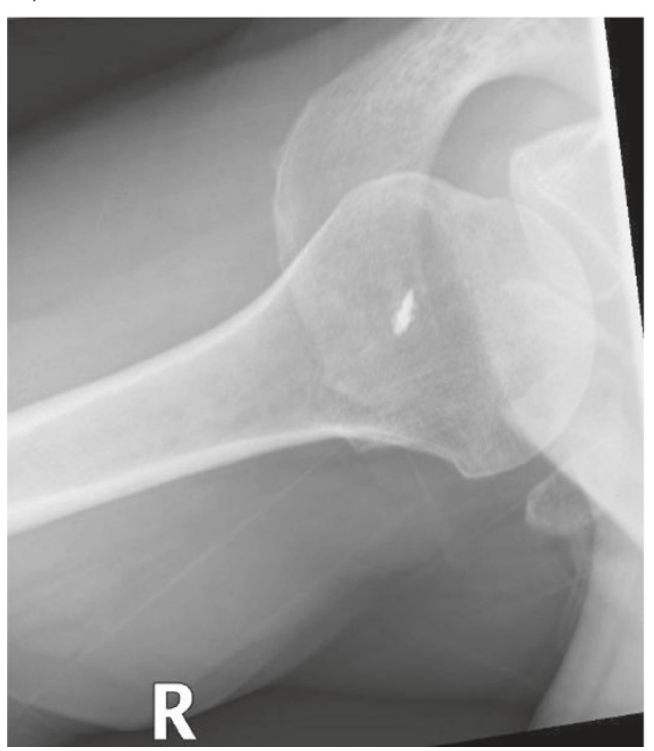

Figure 1 Anteroposterior (a) and axillary (b) radiographs of a patient who had surgery for chronic AC joint dislocation with autogenous semitendinosus and gracilis tendon grafts 4 years previously. Marked osteolysis has developed to the lateral clavicle. This patient also suffered a fracture of the coracoid process.

to 86 in female (Katolik et al. 2005; Yian et al. 2005). The mean CS in the injured shoulder (male 84, female 73) was in both genders 10 points less than the normal value. The difference from normal values may reveal a tendency not to recover fully to the normal level after surgery.

Our study's mean value for DASH score (14) did not differ from the normative score (10.1) (Hunsaker et al. 2002). The minimal detectable change (MDC) in DASH score is 10.5 (Roy et al. 2009). Thus, only values more than 21 in DASH score would have indicated deterioration from normal.

The reconstructive surgery does not always ensure AC joint stability. Almost half our patients suffered clinical AC joint instability after surgery. Tunnel widening may ruin stability by preventing tendon-to-bone healing. We used PLLA (poly-l-lactide acid) and PEEK (polyetheretherketone) tenodesis screws. Tunnel widening occurred similarly with both screws, with no apparent relation to screw material.

Tauber et al. (2007; 2009) and Yoo et al. (2010) have published results of chronic AC joint dislocation treatment with an autogenous semitendinosus graft. Their surgical techniques were slightly different from those we used, but their objective was similar: reconstruct the CC ligaments anatomically. Their results were encouraging in relation to functional recovery, pain-relief, patient satisfaction, and radiological findings.

Results of surgery in chronic AC joint dislocation are inferior to those in acute surgery. Von Heideken et al. 


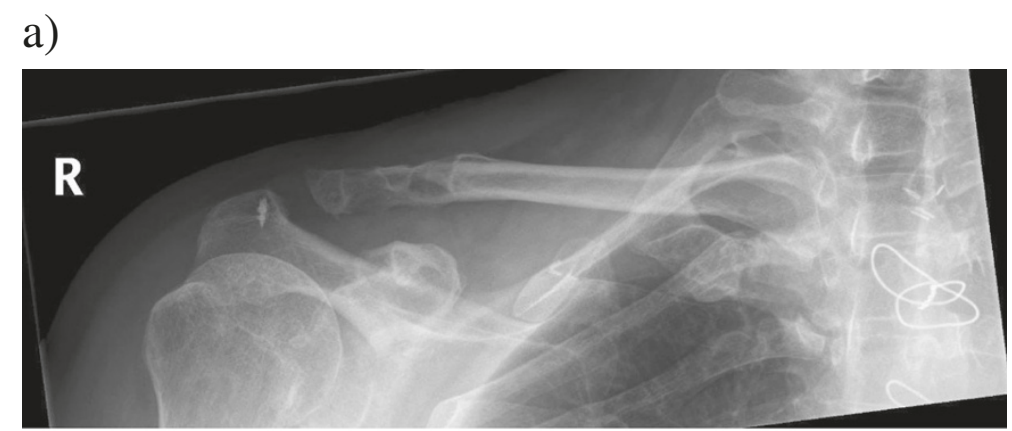

b)

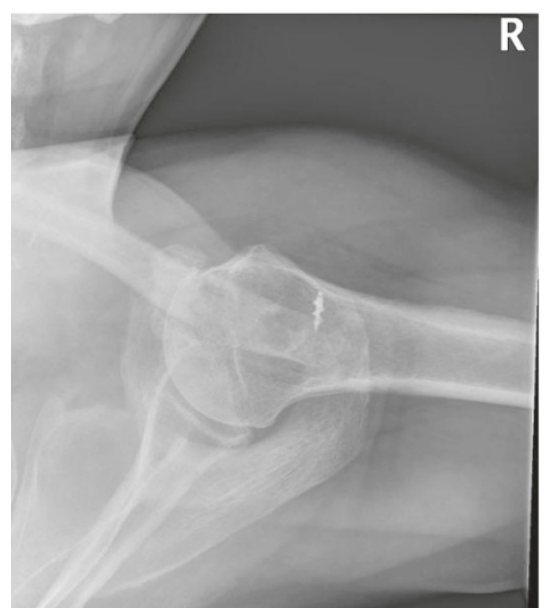

Figure 2 Anteroposterior (a) and axillary (b) radiographs of a patient after surgery for chronic AC joint dislocation. The injury was treated with autogenous semitendinosus and gracilis tendon grafts 5 years before. Notable tunnel widening has appeared in both drill holes. Erosion of the coracoid process is also visible.

(2013) compared Rockwood type-V injury which was treated acutely (within 4 weeks) with a hook plate or after a delay (after 4 months) by a modified WeaverDunn procedure. The acute group scored better in function, disability, pain, and satisfaction. The objectives in acute and in delayed surgery are identical: to stabilize the $\mathrm{AC}$ joint, restore function, and eliminate pain. These fundamental aims seem far more difficult to achieve in delayed surgery. Insufficiency of stabilizing structures,

Table 4 Radiologic results after a mean 4.2 years in the 25 patients treated surgically for chronic AC joint dislocation

\begin{tabular}{lc}
\hline & $\mathbf{n = \mathbf { 2 5 }}$ \\
\hline Normal alignment of AC joint in AP projection & 13 \\
Normal alignment of AC joint in axillary projection & 19 \\
Normal alignment of AC joint in AP and axillary projections & 11 \\
AC osteoarthritis & 1 \\
Lateral clavicle osteolysis & 14 \\
Tunnel widening & 20 \\
Heterotopic ossification & 2 \\
\hline
\end{tabular}

$\mathrm{AC}=$ acromioclavicular.

$\mathrm{AP}=$ anteroposterior. altered anatomical relations, high torsional forces in the lateral clavicle, and the presence of tunnel widening and osteolysis aggravate the site of the surgery and may prevent the success of stabilization.

We noted a high rate of complications. In almost half the patients, the AC joint was clinically unstable. It is comprehensible that the additional AC ligament

Table 5 Clinical and radiological complications after a mean 4.2 years follow-up in the $\mathbf{2 5}$ patients treated surgically for chronic AC joint dislocation

$\mathrm{n}=25$

Wound infection

2

Clinical instability of AC joint $\quad 11$

Tunnel widening $\quad 20$

Lateral clavicle osteolysis $\quad 14$

Incongruency of AC joint (in AP or in axillary radiograph) 14

Fracture of clavicle 3

Fracture of coracoid process 5

Reoperation 4

$\mathrm{AC}=$ acromioclavicular

$\mathrm{AP}=$ anteroposterior. 
Table 6 Influence of osteolysis, tunnel widening, and fracture of the coracoid process on function (CS), disability (DASH), pain (VAS), and AC joint stability in patients treated with autogenous semitendinosus and gracilis tendon grafts for chronic AC joint dislocation

\begin{tabular}{|c|c|c|c|c|c|c|}
\hline & CS injured & CS uninjured & DASH & VAS at rest & VAS at activity & AC joint stable (n) \\
\hline Osteolysis $+(n=14)$ & 78 & 86 & 19 & 2 & 4 & 6 \\
\hline Osteolysis - $(n=11)$ & 88 & 91 & 8 & 1 & 2 & 8 \\
\hline p value & 0.09 & 0.5 & 0.2 & 0.5 & 0.2 & 0.2 \\
\hline Tunnel widening $+(n=20)$ & 83 & 88 & 15 & 1 & 3 & 11 \\
\hline Tunnel widening - $(n=5)$ & 83 & 88 & 11 & 1 & 3 & 3 \\
\hline$p$ value & 1.0 & 0.5 & 0.8 & 0.7 & 0.9 & 1.0 \\
\hline Coracoid fracture $+(n=5)$ & 82 & 92 & 12 & 1 & 3 & 4 \\
\hline Coracoid fracture - $(n=20)$ & 83 & 88 & 15 & 1 & 3 & 10 \\
\hline$p$ value & 0.9 & 0.7 & 0.9 & 0.5 & 0.9 & 0.3 \\
\hline
\end{tabular}

$\mathrm{CS}=$ Constant shoulder Score.

DASH = Disabilities of the Arm, Shoulder, and Hand

VAS $=$ Visual Analog Scale (0-10).

$\mathrm{AC}=$ acromioclavicular.

$+=$ phenomenon exists.

- = phenomenon does not exist.

Results are after a mean 4.2-year follow-up.

reinforcement should secure the stability. Some cadaveric studies have reported encouraging results in clavicle stability after AC ligament reconstruction (Gonzalez-Lomas et al. 2010; Michlitsch et al. 2010). In a recent randomized comparative study (semitendinosus graft vs. synthetic ligament) was found lateral clavicle osteolysis in $95 \%$ of patients (Fauci et al. 2013). In our study, tunnel widening and lateral clavicle osteolysis were also remarkably common. Failure to stabilize the AC joint may be a consequence of unsatisfactory tendon-bone integration and graft incorporation. In many patients, the osteolysis affected the lateral clavicle as far as to the drill holes, causing graft loosening and instability. In only 1 patient was the osteolysis visible in the preoperative radiographs. The surgery-induced osteolysis may have been the result of a disturbance in the bone-blood circulation. Surgical dissection, clavicle drilling, or tenodesis screws may disturb blood perfusion in bone, leading to significant osteolysis. Despite the numerous complications, the patient satisfaction in surgery was surprisingly high. It would seem as complications have only minor negative effect on daily life.

Some studies discuss the arterial supply of the clavicle. Knudsen et al. (1989) found that the primary supply of the clavicle is periosteal through numerous Volkmann canals into the cortex. They found no well-developed nutrient artery. Havet et al. (2008) also found periosteal vascularisation to be the main blood supply to the clavicle. They also noticed nutrient foramina at the lateral end of the clavicle in all cases. One theory is that arterial supply to the clavicle is by the nutrient artery. Fischer and Carret (1978) found a branch of the suprascapular artery that penetrated into the clavicle via the foramina at the level of the middle-lateral third union. Certainly, some of the circulation comes also via muscle attachments. Because of chronic dislocation and stiffness of the soft tissue around the clavicle, the detachment and mobilization has to be thorough. During this detachment, the arterial supply (periosteal, nutrient artery, and muscle attachments) may undergo damage, resulting surprisingly fast in dissolution of the bone mineral, cyst formation, and finally osteolysis.

During follow-up, fractures of the coracoid process and clavicle were common. All fractures in the clavicle were in the medial drill hole; in only 1 patient did the fracture emerge due to a new injury. In 2 patients, fracture of the coracoid process was associated with a radiological cranial dislocation of the clavicle. We think that non-absorbable sutures may cause the coracoid fractures by gradually stressing or cutting the bone as suggested previously (Kippe et al. 2009). Non-absorbable sutures may offer some extra support to the tendon grafts during the healing period. When risk for stress fracture in the coracoid process is as high as in our study, it might be reasonable to avoid such sutures.

In our surgical method, the missing CC ligaments were reconstructed with autogenous tendon grafts. Nonabsorbable sutures provided strength for this reconstruction. Some biomechanical studies discuss the importance of AC and CC ligaments. Urist (1946) found in his cadaver study that when CC ligaments are transected, the intact $\mathrm{AC}$ ligament can prevent joint dislocation. He also demonstrated how the gradual sectioning of $\mathrm{AC}$ and $\mathrm{CC}$ ligaments and muscle attachments leads to complete disarticulation. The AC ligament acts as the primary structure to prevent posterior displacement of the 
clavicle. The AC ligament also plays an important role in preventing superior displacement. Fukuda et al. (1986) noticed that when the clavicle is pulled upward, the first structure to resist the dislocation is the AC ligament. They discovered that the AC ligament produces two-thirds of the restraining forces against superior displacement by a lesser amount of displacement and induced load. By larger displacement and induced load, the conoid ligament played the major role. We think that in delayed surgery, the AC ligament should also be reconstructed with the tendon graft. AC ligaments are short, and in reconstruction this structure should be imitated (Stine and Vangsness 2009). Clavicular and acromial graft attachments to bone should be as close as possible to the superior and posterior part of the $\mathrm{AC}$ joint line.

Our study has certain limitations. As we could not examine all the patients treated with tendon grafts, some selection bias may have occurred. Surgery was not entirely standardized during the study period. Some minor modifications in surgical technique occurred over the course of time. We believe, however, that this had no major impact on results. Reconstructive surgery on CC ligaments is a demanding procedure; hence, results of surgery may be better in those patients treated in the later part of the series. The study was retrospective, leaving us unsure of the precise level of function or disability before the reconstructive surgery.

In future, what would be valuable is to compare longterm results of reconstructive surgery and nonoperative treatment in chronic AC joint dislocation. We should also determine the accurate mechanism and cause of osteolysis in delayed surgery to prevent the undesirable consequences of this complication.

\section{Conclusion}

The aim of reconstructive surgery is to eliminate pain and discomfort by stabilizing the $\mathrm{AC}$ joint and maintaining, or even improving, shoulder function. Despite the surgery, almost half the AC joints failed to stabilize and also the shoulder function was inferior compared to uninjured side. Tunnel widening and lateral clavicle osteolysis were common and might ruin the results. Anatomic reconstruction of CC ligaments showed a moderate subjective outcome at the 4-year follow-up. Most patients were satisfied to the results of surgery, although radiological findings were unsatisfactory. Because of the importance of the AC ligament for clavicular stability, we recommend repairing the superior and posterior portion of the $\mathrm{AC}$ ligament in delayed surgery.

\section{Competing interests}

Our study was supported by Helsinki University Central Hospital Research Funds. The funder had no role in study design, data collection and analysis, decision to publish, or reporting the manuscript. The authors declare that they have no competing interests.

\section{Authors' contributions}

KV searched for the patient information from hospital records, examined all patients, analyzed the data, and wrote the primary manuscript. VS made the surgery for all patients, participated in patient information retrieval, in data analyses, and in the design of the study. IT participated in data analyses and revised the manuscript critically for important intellectual content. VR participated in the design of the study and revised the manuscript critically for important intellectual content. $\mathrm{VH}$ analyzed all preoperative and postoperative radiographs and participated in the design of the study concerning radiology. JP participated in the design of the study and revised the manuscript critically for important intellectual content. J-MB helped to draft the manuscript and revised the manuscript critically for important intellectual content. MP participated in the design of the study and coordination, helped to draft the manuscript, and participated in statistical analyses. All authors read and approved the final manuscript.

\section{Acknowledgments}

Carolyn Brimley Norris, PhD, University of Helsinki Language Services.

\section{Author details}

${ }^{1}$ Department of Surgery, Helsinki University Central Hospital and University of Helsinki, Topeliuksenkatu 5, Helsinki 00260, Finland. ${ }^{2}$ Department of Radiology, Helsinki Medical Imaging Centre, Helsinki University Central Hospital, Topeliuksenkatu 5, Helsinki 00260, Finland. ${ }^{3}$ Centre for Health and Social Economics, Institute for Health and Welfare, PL 30, Helsinki 00271, Finland.

Received: 18 March 2014 Accepted: 18 July 2014

Published: 10 August 2014

\section{References}

Adam FF, Farouk O (2004) Surgical treatment of chronic complete acromioclavicular dislocation. Int Orthop 28(2):119-122, doi:10.1007/s00264-003-0520-3

Bannister GC, Wallace WA, Stableforth PG, Hutson MA (1989) The management of acute acromioclavicular dislocation. A randomised prospective controlled trial. J Bone Joint Surg Br 71(5):848-850

Boileau P, Old J, Gastaud O, Brassart N, Roussanne Y (2010) All-arthroscopic Weaver-Dunn-Chuinard procedure with double-button fixation for chronic acromioclavicular joint dislocation. Arthroscopy 26(2):149-160, doi:10.1016/j. arthro.2009.08.008

Bostrom Windhamre HA, von Heideken JP, Une-Larsson VE, Ekelund AL (2010) Surgical treatment of chronic acromioclavicular dislocations: a comparative study of Weaver-Dunn augmented with PDS-braid or hook plate. J Shoulder Elbow Surg 19(7):1040-1048, doi:10.1016/j.jse.2010.02.006

Fauci F, Merolla G, Paladini P, Campi F, Porcellini G (2013) Surgical treatment of chronic acromioclavicular dislocation with biologic graft vs synthetic ligament: a prospective randomized comparative study. J Orthop Traumatol 14(4):283-290, doi:10.1007/s10195-013-0242-2

Fischer LP, Carret JP (1978) Arterial vascularization of human bones. Bull Assoc Anat (Nancy) 62(179):419-452

Fraschini G, Ciampi P, Scotti C, Ballis R, Peretti GM (2010) Surgical treatment of chronic acromioclavicular dislocation: comparison between two surgical procedures for anatomic reconstruction. Injury 41(11):1103-1106, doi:10.1016/ j.injury.2010.09.023

Fukuda K, Craig EV, An KN, Cofield RH, Chao EY (1986) Biomechanical study of the ligamentous system of the acromioclavicular joint. J Bone Joint Surg Am 68(3):434-440

Galatz LM, Hollis RFJ, Williams GRJ (2009) Acromioclavicular joint injuries. In: Bucholz RW, Heckman JD, Court-Brown CM, Tornetta P (eds) Rockwood and Green's Fractures in Adults, vol 1, 7th edn. Lippincott Williams \& Wilkins (LWW), Philadelphia USA, pp 1210-1224

Gonzalez-Lomas G, Javidan P, Lin T, Adamson GJ, Limpisvasti O, Lee TQ (2010) Intramedullary acromioclavicular ligament reconstruction strengthens isolated coracoclavicular ligament reconstruction in acromioclavicular dislocations. Am J Sports Med 38(10):2113-2122, doi:10.1177/ 0363546510371442

Hamner DL, Brown CH Jr, Steiner ME, Hecker AT, Hayes WC (1999) Hamstring tendon grafts for reconstruction of the anterior cruciate ligament: 
biomechanical evaluation of the use of multiple strands and tensioning techniques. J Bone Joint Surg Am 81(4):549-557

Havet E, Duparc F, Tobenas-Dujardin AC, Muller JM, Delas B, Freger P (2008) Vascular anatomical basis of clavicular non-union. Surg Radiol Anat 30(1):23-28, doi:10.1007/s00276-007-0278-1

Hosseini H, Friedmann S, Troger M, Lobenhoffer P, Agneskirchner JD (2009) Arthroscopic reconstruction of chronic AC joint dislocations by transposition of the coracoacromial ligament augmented by the Tight Rope device: a technical note. Knee Surg Sports Traumatol Arthrosc 17(1):92-97, doi:10.1007/s00167-008-0633-8

Hunsaker FG, Cioffi DA, Amadio PC, Wright JG, Caughlin B (2002) The American academy of orthopaedic surgeons outcomes instruments: normative values from the general population. J Bone Joint Surg Am 84-A(2):208-215

Jeon IH, Dewnany G, Hartley R, Neumann L, Wallace WA (2007) Chronic acromioclavicular separation: the medium term results of coracoclavicular ligament reconstruction using braided polyester prosthetic ligament. Injury 38(11):1247-1253, doi:10.1016/j.injury.2007.05.019

Jones HP, Lemos MJ, Schepsis AA (2001) Salvage of failed acromioclavicular joint reconstruction using autogenous semitendinosus tendon from the knee. Surgical technique and case report. Am J Sports Med 29(2):234-237

Katolik LI, Romeo AA, Cole BJ, Verma NN, Hayden JK, Bach BR (2005) Normalization of the Constant score. J Shoulder Elbow Surg 14(3):279-285, doi:10.1016/j.jse.2004.10.009

Kennedy JC, Cameron H (1954) Complete dislocation of the acromio-clavicular joint. J Bone Joint Surg Br 36-B(2):202-208

Kim SH, Lee YH, Shin SH, Baek GH (2012) Outcome of conjoined tendon and coracoacromial ligament transfer for the treatment of chronic type $\mathrm{V}$ acromioclavicular joint separation. Injury 43(2):213-218, doi:10.1016/j. injury.2011.08.003

Kippe MA, Demetropoulos CK, Baker KC, Jurist KA, Guettler JH (2009) Failure of coracoclavicular artificial graft reconstructions from repetitive rotation. Arthroscopy 25(9):975-982, doi:10.1016/j.arthro.2009.03.016

Knudsen FW, Andersen M, Krag C (1989) The arterial supply of the clavicle. Surg Radiol Anat 11(3):211-214

Lafosse L, Baier GP, Leuzinger J (2005) Arthroscopic treatment of acute and chronic acromioclavicular joint dislocation. Arthroscopy 21(8):1017, doi:10.1016/j.arthro.2005.05.034

LaPrade RF, Hilger B (2005) Coracoclavicular ligament reconstruction using a semitendinosus graft for failed acromioclavicular separation surgery. Arthroscopy 21(10):1277, doi:10.1016/j.arthro.2005.07.020

Michlitsch MG, Adamson GJ, Pink M, Estess A, Shankwiler JA, Lee TQ (2010) Biomechanical comparison of a modified Weaver-Dunn and a free-tissue graft reconstruction of the acromioclavicular joint complex. Am J Sports Med 38(6):1196-1203, doi:10.1177/0363546509361160

Millett PJ, Braun S, Gobezie R, Pacheco IH (2009) Acromioclavicular joint reconstruction with coracoacromial ligament transfer using the docking technique. BMC Musculoskelet Disord 10:6, doi:10.1186/1471-2474-10-6

Pavlik A, Csepai D, Hidas P (2001) Surgical treatment of chronic acromioclavicular joint dislocation by modified Weaver-Dunn procedure. Knee Surg Sports Traumatol Arthrosc 9(5):307-312, doi:10.1007/s001670100222

Roy JS, MacDermid JC, Woodhouse $\sqcup$ (2009) Measuring shoulder function: a systematic review of four questionnaires. Arthritis Rheum 61(5):623-632, doi:10.1002/art.24396

Shetty NS, Yoo YS, Kim do Y, Lee SS, Jeong US (2009) Open anatomical coracoclavicular ligament reconstruction using a tendon graft with an Endobutton loop. Acta Orthop Belg 75(6):828-831

Song HS, Song SY, Yoo YS, Lee YB, Seo YJ (2012) Symptomatic residual instability with grade II acromioclavicular injury. J Orthop Sci 17(4):437-442, doi:10.1007/s00776-012-0239-3

Stine IA, Vangsness CT Jr (2009) Analysis of the capsule and ligament insertions about the acromioclavicular joint: a cadaveric study. Arthroscopy 25(9):968-974, doi:10.1016/j.arthro.2009.04.072

Tauber M, Eppel M, Resch H (2007) Acromioclavicular reconstruction using autogenous semitendinosus tendon graft: results of revision surgery in chronic cases. J Shoulder Elbow Surg 16(4):429-433, doi:10.1016/j. jse.2006.10.009

Tauber M, Gordon K, Koller H, Fox M, Resch H (2009) Semitendinosus tendon graft versus a modified Weaver-Dunn procedure for acromioclavicular joint reconstruction in chronic cases: a prospective comparative study. Am J Sports Med 37(1):181-190, doi:10.1177/0363546508323255
Urist MR (1946) Complete dislocations of the acromiclavicular joint; the nature of the traumatic lesion and effective methods of treatment with an analysis of forty-one cases. J Bone Joint Surg Am 28(4):813-837

von Heideken J, Bostrom Windhamre H, Une-Larsson V, Ekelund A (2013) Acute surgical treatment of acromioclavicular dislocation type $\mathrm{V}$ with a hook plate: superiority to late reconstruction. J Shoulder Elbow Surg 22(1):9-17, doi:10.1016/j.jse.2012.03.003

Weaver JK, Dunn HK (1972) Treatment of acromioclavicular injuries, especially complete acromioclavicular separation. J Bone Joint Surg Am 54(6):1187-1194

Yian EH, Ramappa AJ, Arneberg O, Gerber C (2005) The Constant score in normal shoulders. J Shoulder Elbow Surg 14(2):128-133, doi:10.1016/j.jse.2004.07.003

Yoo JC, Ahn JH, Yoon JR, Yang JH (2010) Clinical results of single-tunnel coracoclavicular ligament reconstruction using autogenous semitendinosus tendon. Am J Sports Med 38(5):950-957, doi:10.1177/0363546509356976

doi:10.1186/2193-1801-3-420

Cite this article as: Virtanen et al:: Surgical treatment of chronic acromioclavicular joint dislocation with autogenous tendon grafts. SpringerPlus 2014 3:420

\section{Submit your manuscript to a SpringerOpen ${ }^{\odot}$ journal and benefit from:}

- Convenient online submission

- Rigorous peer review

- Immediate publication on acceptance

- Open access: articles freely available online

- High visibility within the field

- Retaining the copyright to your article

Submit your next manuscript at $\gg$ springeropen.com 